\title{
A HISTÓRIA DA LUTA EM DEFESA DA EDUCAÇÃO PÚBLICA NO BRASIL: questões para pesquisa ${ }^{1}$
}

\author{
Lucelma Silva Braga ${ }^{2}$
}

\begin{abstract}
RESUMO
Este trabalho objetiva apontar alguns elementos, ainda em caráter preliminar, da história da luta em defesa da educação pública no Brasil no período compreendido entre a década de 1980 e anos 2000. As condições geradas com o alto endividamento externo e a fragilização das bases da economia nacional tornou a década de 1980 fecunda para a organização política da classe trabalhadora de modo geral e para o campo educacional, em particular, resultando numa organização de força coletiva sem precedentes na história da educação brasileira. A partir da década de 1990, com as reformas educacionais implementadas no bojo do Estado neoliberal e o avanço da ofensiva das classes dominantes pela hegemonia do capital, temos visto que o movimento de educadores passou por um processo de refreamento de sua capacidade de luta coletiva em âmbito nacional. A retomada de formas de resistência e enfrentamento coletivos, capazes de alterarem as condições históricas da educação brasileira, exige, entre outras coisas, compreender em profundidade as especificidades dessa história de luta dos educadores para apreender-se lições que sinalizem quais são os elementos fundamentais na conjuntura atual de desenvolvimento das crises do capitalismo.

Palavras-chave: Movimento Docente; Educação Pública; Capitalismo.
\end{abstract}

\section{THE FIGHT HISTORY IN DEFENSE OF PUBLIC EDUCATION IN BRAZIL: QUESTIONS FOR RESEARCH}

\begin{abstract}
This paper aims to point out some elements, even on a preliminary basis, the defense struggle in the history of public education in Brazil in the period between the 1980s and 2000s the conditions generated by the high external debt and the weakening of the foundations of the economy National became the 1980s fruitful for the working class political organization in general and the educational field, in particular, resulting in an unprecedented collective strength of the organization in the history of Brazilian education. From the 1990s, with the educational reforms implemented in the wake of the neoliberal state and the progress of the offensive of the ruling classes by the hegemony of capital, we have seen that the movement of educators underwent a containment process of collective struggle capability nationwide. The resumption of collective forms of resistance and confrontation, capable of changing historical conditions of Brazilian education requires, among other things, to understand in depth the specifics of this history of struggle of the educators to apprehend lessons that identify what are the key elements in current situation of development of capitalist crises.
\end{abstract}

Keywords: Teacher Movement, Public Education, Capitalism 
O dinamismo econômico do período compreendido entre o final da década de 1960 e a primeira metade da década de 1970 foi se arrefecendo em decorrência das consequências da política econômica adotada, que produziu alto endividamento externo e fragilizou as bases da economia nacional. O chamado "milagre econômico" foi uma saída comum a muitos países periféricos, "que se tornaram receptores privilegiados de capitais estrangeiros, até 1973 abundantes no mercado internacional" (MINTO, 2013, p. 248).

Com a crise internacional, as contradições internas se acirraram e se expressaram na redução do padrão de vida da maioria da população, causando desemprego, alta inflação, entre outros. Essas contradições impulsionaram o chamado 'projeto de abertura', "com o qual o governo Geisel buscou enfrentar o início do declínio do regime, cujo primeiro sintoma foi a derrota do governo nas eleições parlamentares de 1974" (COUTINHO, 2007, p. 187).

Nesse cenário, a sociedade civil emergente terminou por promover uma abertura bem mais radical do que a prevista no projeto originário do governo Geisel-Golbery" (idem, ibidem), criando uma atmosfera mais favorável para as lutas pela democratização da sociedade, o que resultou numa progressiva organização de setores da classe trabalhadora.

O Brasil que adentrou a década de 1980 era um país com fortes desequilíbrios no setor público e no endividamento externo. Fatores estes que, combinados com a difícil situação social (que ajudaram a agravar), fragilizaram de tal maneira a estratégia econômica da Ditadura e influenciaram diretamente em seu declínio político. A crise brasileira não era, portanto, um evento isolado, mas resultava da própria conjuntura capitalista internacional, que exigia mudanças estruturais para garantir a acumulação e expansão de capital (MINTO, 2013, p.249).

\section{O CENÁRIO DE LUTA EM DEFESA DA EDUCAÇÃO PÚBLICA NA DÉCADA DE 1980 NO BRASIL: APROXIMAÇÕES}

Ao contrário da avaliação feita pelos setores ligados à economia, de que a década de 1980 foi uma "década perdida" os últimos anos da década de 1970 e os anos da década de 1980, foram de muitas conquistas para os setores da classe trabalhadora ligados à educação.

Conforme Saviani (2007, p. 400), a organização política do campo educacional nesta que "foi a década mais fecunda de nossa história", permite-nos compará-la, nesses termos, apenas à década de 1920, embora os efeitos da organização dos professores na década de 1980, pareçam ter ultrapassado os efeitos daquela, segundo ele. Resultou da também efervescente década de 1920, a criação da Associação Brasileira de Educação$\mathrm{ABE}$ que reuniu, inicialmente, interessados de diversas tendências em defesa da educação.

A Associação Brasileira de Educação teve importante papel nas lutas em defesa da educação até a década de 1950, influenciando, inclusive a política educacional do governo Vargas, na medida em que foi a IV Conferência Nacional da Educação organizada pela Associação em dezembro de 1931, "a origem mais imediata da sistematização do documento" [Manifesto dos Pioneiros da Educação Nova] que deu em certa medida o “'sentido pedagógico' da Revolução", em um período que o grupo de renovadores vinha ampliando, ainda mais, seu leque de influência no interior do aparelho do Estado (WARDE, 1982, p. 8). 
Segundo Rosar (2005, p. 3), uma das características mais relevantes que diferencia os educadores "críticos" da década de 1980, dos renovadores da década de 1920, foi o fato de que os primeiros mantiveram "relação orgânica entre a atuação acadêmica e a inserção em espaços públicos de debate e de luta social e política", enquanto os renovadores "ocuparam a burocracia do Estado".

A primeira geração de educadores que surgiu no cenário nacional da década de 1920 por meio do amplo movimento nacional que resultou em importantes reformas em âmbito estadual encontrava-se, de acordo com Rosar (2005, p. 6), "nas hostes do estado", "diferentemente dos representantes do pensamento crítico nos anos 80 e 90" [...] que "ocupavam os espaços possíveis de debate e de divulgação de novas perspectivas de análise da educação, indicando-a como dimensão efetiva do processo de transformação da realidade social do país".

Em análise acerca da organização política dos educadores na década 1980, Saviani (2007, p. 402) afirma que esta é caracterizada por meio de dois vetores distintos:

[...] aquele caracterizado pela preocupação com o significado social e político da educação, do qual decorre a busca de uma escola pública de qualidade, aberta a toda a população e voltada precipuamente para as necessidades da maioria, isto é, a classe trabalhadora; e outro marcado pela preocupação com o aspecto econômico-corporativo, portanto, de caráter reivindicativo, cuja expressão mais saliente é dada pelo fenômeno das greves que eclodiram a partir do final dos anos de 1970 e se repetiram em ritmo, freqüência e duração crescentes ao longo da década de 1980.

O vetor cuja preocupação central era com o significado social e político da educação é representado pelas entidades de cunho acadêmico-científico. É notável a expansão quantitativa e qualitativa da produção intelectual dos educadores no período, que se destacou, especialmente, pelo esforço em compreender o fenômeno educativo a partir de seus condicionantes econômico, sociopolítico e ideológico. Nesse sentido, um volume extraordinário de trabalhos acadêmicos dos mais diversos matizes e de diferentes focos de análise fez parte deste movimento, entre os quais podemos citar Arelaro (1980), Cury (1978), Cunha (1975), Cunha e Góes (1985), Buffa (1979), Félix (1984), Freitag (1977), Frigotto (1984), Germano (1985), Libâneo (1985), Ribeiro (1979), Sanfelice (1986), Saviani (1979), Warde (1984), Xavier (1984), entre outros.

A expansão dos programas de pós-graduação no país contribuiu decisivamente para o visível avanço em termos de produção de um pensamento crítico e referenciado socialmente, levando os educadores insatisfeitos com a atmosfera [objetiva e subjetiva] gerada pelos governos militares a organizarem-se "em espaços públicos de debate e de luta social e política" (ROSAR, 2005, p. 4).

Para Luiz Antônio Cunha (1991, p.93), “o ano de 1978 foi especialmente fértil para o processo de organização do campo educacional”. A intensificação do movimento, decorrência da anistia aos presos políticos do governo militar, levou à deflagração das primeiras greves do magistério oficial em vários estados do país, culminando com a criação de duas importantes entidades do campo educacional, a Associação Nacional de Pós-Graduação em Educação - ANPEd e o Centro de Estudos Educação e Sociedade, o CEDES.

Meses depois, já no ano de 1979, foi criada também a Associação Nacional de Educação (ANDE) que, junto com a ANPEd e o CEDES, promoveram, a partir de 1980, a 
conhecida série de Conferências Brasileiras de Educação. As temáticas priorizadas para o debate nas seis conferências realizadas entre o mês de abril de 1980 a setembro de 1991, permitem-nos compreender o caráter das discussões feitas pelo movimento de educadores à época.

A I Conferência Brasileira de Educação realizada na Pontifícia Universidade Católica de São Paulo (PUC/SP), com a participação de 1,4 mil pessoas teve como tema central "A política educacional". Já a II Conferência Brasileira de Educação, realizada na Universidade Federal de Minas Gerias (UFMG), em Belo Horizonte, em junho de 1982, teve seu público ampliado para 2 mil participantes e tematizou "A educação na perspectiva de democratização da sociedade”. A III Conferência Brasileira de Educação, ampliou o número de participantes para 5 mil, foi realizada em outubro de 1984, na Universidade Federal Fluminense (UFF), em Niterói, e debateu o tema "Da crítica às propostas de ação". "A Educação e a Constituinte" foi o tema discutido na IV Conferência Brasileira de Educação, realizada em setembro de 1986, na Universidade Federal do Goiás (UFG) e na Universidade Católica de Goiás (UCG), ambas na cidade de Goiânia, com 6 mil participantes. A quinta reunião foi sediada pela Universidade de Brasília (UnB), realizada em agosto de 1988, contando com 6 mil participantes e teve como tema central "A lei de diretrizes e bases da educação nacional" (CUNHA, 1991, pp. 94-95) e por fim, fechando a série das Conferências, a VI CBE, foi realizada em setembro 1991, na Universidade de São Paulo (USP), com a participação de mais de 6 mil educadores e teve como tema "A Política Nacional de Educação" (BOLLMANN, 2010, p. 664).

O foco de discussão das Conferências que inspirou um número expressivo de educadores no período revela o claro entendimento das questões candentes de seu tempo, bem como sua inclusão na pauta política, manifestando-se especialmente através da estratégia de luta ideológica. Vale a pena ressaltar que em consonância com a referida estratégia, a Associação Nacional da Educação (ANDE) editou no período de 10 anos compreendido entre 1981 a 1990 - um periódico semestral que tinha como objetivo "o desenvolvimento da educação pública no âmbito do que hoje é chamado de educação básica, procurando articular a produção teórica que se adensava nas universidades com o trabalho pedagógico das escolas" (SAVIANI, 2007, p. 408).

Também criada como parte da estratégia de luta ideológica, a revista semestral Educação e Sociedade circulou, a partir de setembro de 1978, entre os professores universitários, estudantes de graduação e pós-graduação, mantendo desde então sua publicação, com os mais variados temas de interesse para a área educacional.

O segundo vetor corresponde à organização de entidades sindicais, cuja "motivação dominante, é de caráter econômico-corporativo" [...] "articuladas em âmbito nacional pela CNTE e Andes" (SAVIANI, 2007, p. 403).

Devido ao clima favorável de luta pelas históricas demandas da classe trabalhadora em sentido amplo, o caráter econômico-corporativo das entidades sindicais foi "evoluindo de modo que incorporasse progressivamente preocupações econômico-políticas e, mesmo, especificamente, político-pedagógica" (idem, ibidem), numa dinâmica ascendente e rica de amadurecimento da categoria de trabalhadores da educação.

O processo de luta que transformou a antiga Confederação de Professores do Brasil (CPB), criada em 1960, na Confederação Nacional dos Trabalhadores da Educação (CNTE), no final dos anos 1980, revela a ampliação horizontal, no sentido de ter aumentado significativamente a sua base articulando numa mesma entidade os trabalhadores da educação (professores, especialistas e funcionários das escolas públicas) 
e não apenas os professores de $1^{\circ}$ e $2^{\circ}$ graus, e vertical, o que é indicado pelas reivindicações de caráter mais amplo, que resultam de uma consciência mais clara e ampliada acerca das reais necessidades da classe.

Do mesmo modo, a Associação Nacional de Docentes do Ensino Superior - a ANDES, criada em 1981, num Congresso Nacional de Docentes do Ensino Superior, realizado em Campinas-SP, teve importante papel na luta pelas conquistas da classe trabalhadora em matéria de educação, papel este traduzido em várias de suas teses, entre elas, a defesa do sistema nacional de educação pública, o projeto de Lei de Diretrizes e Bases da Educação Nacional (LDB) e de universidade. O caráter combativo desta entidade, que foi transformada em 1988 , no Sindicato Nacional dos Docentes das Instituições do Ensino Superior (ANDES- SN) se manteve durante toda a década de 1990, com a realização de greves da categoria, como a que ocorreu em 1991, que chegou a paralisar professores e técnicos-administrativos de 45 Instituições Federais de Ensino Superior (IFES), por 107 dias.

Conforme Navarro (2001, p. 149-150), já em 1979, portanto, antes mesmo da criação da Associação, propriamente dita, no I Encontro Nacional de Associações de Docentes (I ENADE), que reuniu representantes de 23 Associações Docentes (AD’s) e 3 Comissões Pró-AD’s, encontro que foi decisivo para a criação da entidade, foram aprovadas as propostas do movimento, agrupadas em três eixos: 1) Democratização $e$ autonomia, "voltado para a articulação nacional das lutas pela autonomia universitária [...] e planejamento de ações sistemáticas e organizadas contra todo tipo de perseguição"; 2) Políticaeducacional, como expressão de um "firme posicionamento contra a ampliação do ensino particular e pela contínua expansão da gratuidade do ensino, através da elevação do montante de verbas públicas para a educação"; 3) Organização sindical, "centrado na defesa da 'liberdade, autonomia e unidade sindical"' (apud MACIEL, 1991, p. 72).

A efervescência dos movimentos empreendidos nos anos 1980 levou a constituição do Fórum Nacional da Educação na Constituinte em Defesa do Ensino Público e Gratuito, na UnB. O Fórum teve como ponto de partida as questões gerais abordadas na Carta de Goiânia, aprovada em sessão plenária de encerramento da IV Conferência Brasileira de Educação, em Goiânia em 1986. Às diretrizes básicas da Carta de Goiânia foram acrescentadas as reivindicações específicas de entidades sindicais, pesquisadores e de intelectuais, resultando "na plataforma mais avançada até então formulada no país" (CUNHA, 1991, p. 432).

Entre as questões mais relevantes é possível destacar a defesa intransigente "e sem eufemismos" (idem, p. 433) da destinação de recursos públicos com exclusividade para o setor público - questão de peso no embate entre os setores público e privado - o aumento de percentuais destinados à educação pública por esfera administrativa (União, estados e municípios), gestão democrática dos recursos destinados às instituições de ensino e pesquisa, com a "criação de organismos de controle com a participação de estudantes, professores, funcionários e pais de alunos, assim como representantes das sociedades científicas e das entidades da classe trabalhadora" (idem, ibidem).

Com esta plataforma o Fórum conseguiu o apoio, no curtíssimo período de abril a junho de 1987, de 279 mil pessoas, entre os quais 195.186 da ainda Confederação de Professores do Brasil (futura CNTE) e filiadas; 22.764 da Associação Nacional de Docentes do Ensino Superior (ANDES); 10.253, da União Nacional dos Estudantes (UNE); 7.350 da Associação Nacional da Educação (ANDE); 7.144 da Associação Nacional de Pós-Graduação em Educação (ANPEd), 5.531 da Associação Nacional de 
Política e Administração da Educação (ANPAE); 5.023 da Federação de Sindicatos de Trabalhadores Técnico-administrativos em Instituições de Ensino Superior Públicas no Brasil (FASUBRA); 3.136 do Centro de Estudos Educação e Sociedade (CEDES); 2.564 da Federação Nacional de Orientadores Educacionais (FENOE) ; 2.339 da Comando Geral dos Trabalhadores (CGT); 639 da Sociedade de Estudos e Atividades Filosóficas (SEAF); 256 da Central Única dos Trabalhadores (CUT), 68 da União Brasileira de Estudantes Secundaristas (UBES) e o total de 16.760 de outras entidades não identificadas (idem, p. 469).

A participação das entidades que compunham o Fórum na Comissão de Educação da Câmara dos Deputados foi decisiva para os avanços logrados, embora não seja possível afirmar que na montagem do texto Constitucional tenha prevalecido a plataforma elaborada pelos setores mais progressistas. O embate com os setores privatistas limitou o avanço, de modo que na questão considerada central prevaleceu a estratégia da conciliação, permanecendo a coexistência de instituições públicas e privadas, com a destinação de recursos do erário público para ambos os setores.

Em obra intitulada Nova República?, Florestan Fernandes (1986, p. 19), analisa a dinâmica de transição do regime ditatorial ao regime de democracia formal e afirma não ter sido uma vitória da democracia [real], mas uma nova derrota do republicanismo. Não obstante a força política de alguns setores da classe trabalhadora, entre eles, os trabalhadores da educação, ter resultado em conquistas significativas, não foi possível avançar rumo à implementação efetiva das bandeiras, construídas e içadas, coletivamente.

A referida transição produziu a aparência de incorporação das demandas dos setores historicamente excluídos da sociedade brasileira, embora, na prática, tenha tornado "impraticável qualquer saída que ultrapassasse a continuidade da ordem existente em sua forma urgente" (idem, p. 20). De acordo com Fernandes, "a Nova República [...] não combateu de frente a ditadura. Contornou-a e prolongou-a" (idem, ibidem), num processo em que o governo foi gradativamente subtraindo a iniciativa dos movimentos sociais e políticos e convertendo o debate e a mobilização nas bases em estudo de cúpula e trabalho de comissões técnicas.

O chamado assim 'entrismo' e o espírito de 'conciliacionismo' a qualquer preço como medidas de 'defesa da democracia' não resguardam os interesses das classes trabalhadoras e os objetivos dos seus partidos. Ao contrário, oferecem quase de graça um respiro às classes dominantes à sua estratégia de explorar a transição lenta, gradual e segura como um expediente para montar um Estado de segurança nacional com as aparências de um 'Estado de direito' (FERNANDES, 1986, p. 32).

A necessidade de reestruturação no âmbito da política é uma exigência da própria reestruturação produtiva, conforme Pinassi (2011). A autora destaca que isso ocorre no país há pelo menos duas décadas, reduzindo ainda mais, no contexto da reversão neoliberal, a democratização restrita do período pós-ditadura.

\section{O AJUSTE NEOLIBERAL NA DÉCADA DE 1990 E OS EFEITOS NA LUTA EM DEFESA DA EDUCAÇÃO PÚBLICA}

No segundo quinquênio da década de 1990, com a eleição do governo de Fernando Henrique Cardoso para o período de 1995-1998, posteriormente prolongado para mais um mandato (1999-2002), ocorreram "modificações significativas na concepção de 
democracia e do papel da sociedade brasileira no mundo globalizado", de acordo com Arelaro (2000, p. 99).

As profundas transformações implementadas neste período, ligadas à necessidade de adaptar o país, ao novo padrão global de acumulação capitalista, foram decisivas para o arrefecimento dos movimentos de luta e a substituição da estratégia ofensiva adotada pelos setores progressistas da década de 1980, por uma estratégia mais defensiva. Segundo Leher, ocorreu, uma "redução abrupta do número de greves anuais" de cerca "2,5 mil por ano em 1989 para menos de 500 greves no final da década”(LEHER, 2014, p. 02).

[...] o capital - operando também por meio do Estado - impôs transformações ainda mais profundas na educação da classe trabalhadora. A perspectiva universalista de que a escola pública deveria assegurar uma formação geral igualitária a todos os estudantes por meio da garantia, pelo Estado, da educação pública, gratuita e estruturada em sistemas nacionais, foi combatida em prol de políticas focalizadas, referenciadas na pedagogia das competências, atributos utilitaristas que objetivam a adaptação das crianças e jovens ao ethos capitalista e, mais precisamente, ao chamado novo espírito do capitalismo flexível, fundamentado no trabalho superexplorado e precário (idem, ibidem).

Ainda demonstrando a força política da experiência de luta desenvolvida na efervescente década de 1980, as entidades reunidas no Fórum Nacional em Defesa da Escola Pública promoveram, a partir de 1996, em todo o território nacional, inúmeras atividades que antecederam e garantiram a realização dosCongressos Nacionais de Educação (CONED’s), que culminou com a consolidação da proposta de Plano Nacional da Educação - PNE, oriunda dos setores progressistas da sociedade civil organizada. Embora o PNE do Fórum não tenha sido referência para a política educacional oficial, sua elaboração coletiva atesta, sem sombra de dúvida, a capacidade que tiveram os referidos setores de organizar-se e propor alternativas para os problemas educacionais do país.

As significativas perdas no texto da LDB (Lei 9394/96) e posteriormente do PNE, acentuaram, ainda mais, a tendência marcante da história da educação brasileira: o privatismo. A ênfase no protagonismo das famílias e da sociedade de modo geral na responsabilização das oportunidades educacionais em detrimento do papel do Estado em financiá-las, assegurando-as em todos os níveis, tornou nítidas as perdas sofridas no histórico embate da educação nacional.

O saldo, após duas décadas de implementação da reforma educacional inspirada no receituário neoliberal e orquestrada pelos organismos internacionais como o Fundo Monetário Internacional, Banco Mundial, entre outros, é dramático. Um exemplo contundente, entre outros possíveis, da penetração da agenda do capital na educação pública é a chamada "reconversão docente" que implica no processo de alargamento do conceito de docência e a constituição de um superprofessor - com muitas tarefas e pouca formação (TRICHES, 2010).

Nesse bojo, observamos forte ênfase na necessidade de adequação das instituições educativas, da educação básica ao ensino superior, convocadas a reformularem seus currículos, "enxugando-os", adequando-os às transformações que vem ocorrendo no âmbito do trabalho produtivo. Tal chamado acentua-se na necessidade de alinhar os processos formativos aos "novos tempos", adequando o homem às exigências, objetivas e subjetivas, postas pelo modo de produção capitalista (JACOMELI, 2004). 
Conforme Shiroma (2003, p. 63), esta lógica inspirou "argumentos utilitaristas que defendem, por exemplo, o enxugamento da formação do professor pela extirpação dos conteúdos que não seriam diretamente aplicados em sala de aula", estabelecendo o que a autora chama de "primazia da prática". Esse movimento tem conduzido os cursos de formação de professores a um crescente esvaziamento do conteúdo crítico e impactado na formação e organização da categoria docente.

Tais transformações que geraram, em certa medida, o esvaziamento da capacidade de leitura histórica da realidade e, consequentemente, da mobilização política, atingiram, o próprio âmbito da produção de conhecimentos na área da educação, promovendo o que Moraes (2011) chamou de "recuo da teoria" com destacadas implicações epistemológicas, éticas e políticas. Segunda a autora (idem, p. 07), entre as determinações possíveis temos, por um lado "a emergência de um ethos neodarwinista nas universidades, com a consequente degradação da vida académica" e, por outro lado, "o ceticismo epistemológico, corrente que trivializa a questão do conhecimento e da verdade e procede a um sutil exercício linguístico", gerando "um novo e pragmático vocabulário destinado a assegurar a obediência e a resignação públicas".

A forte influência do pensamento pós-moderno em educação deve ser entendida nesse contexto. O advento da pós-modernidade se deu associada ao processo ideológico de tentativa de diluição de um referencial crítico, especialmente aquele de cunho marxista, que vinha sofrendo fortes ataques, desde a queda do Muro de Berlim, impactando no pensamento de parte dos educadores que à época "contavam com boas lentes de aumento para a análise do fenômeno educativo" (ROSAR, 2005).

Já em meados da década de 1980, a absorção da suposta crise dos paradigmas filosóficos e científicos delineava o cenário que viria a seguir: a instauração de um novo movimento, articulando a velha dicotomização entre o novo (ou pós) e o velho. Com isso, o discurso novidadeiro foi se fortalecendo e, com ele, o espaço educacional (também o artístico, filosófico e científico) foi sendo tomado pela ênfase no particular, no cotidiano, no efêmero, no imaginário, na cultura, na memória. Na trilha de afirmar a existência de uma profunda crise dos paradigmas, essas elaborações foram sendo impregnadas pelo irracionalismo, pelo subjetivismo e, enfim, no limite, pela perda da própria perspectiva histórica. Penso que, hoje, esse movimento conquistou hegemonia no campo educacional (LOMBARDI, 2010, p. 24).

Isso significa que ao longo das décadas em que se materializavam as políticas neoliberais na área da educação também ocorreu uma forte ofensiva do capital no âmbito da produção acadêmica, destacando-se na historiografia da educação um deslocamento do foco de análise das questões macro estruturais para os fenômenos apreendidos na escala da micro história, dificultando o entendimento acerca do fenômeno educativo e tornando ainda mais urgentes, aos educadores, alcançarem um nível mais ampliado de compreensão dos processos político-pedagógicos, reconhecendo as conexões entre os elementos que se inter-relacionam na produção das políticas públicas por eles executadas, em última instância, e a atuação histórica dos movimentos sociais organizados em torno da defesa da educação pública de qualidade. 
Se ainda conseguimos demonstrar relativa força política nos últimos anos da década de 1990, os primeiros anos do século XXI, especialmente após o governo Lula, registraram a diluição do consenso que unificava as entidades acadêmicas e sindicais. Acerca desse assunto Roberto Leher afirma:

Ao encaminhar uma agenda educacional em grande parte antagônica ao PNE - Proposta da Sociedade Brasileira (CONED) -, os conflitos dos educadores com o governo Lula da Silva não tardaram a tensionar os sindicatos que permaneceram na CUT. Em função de distintas perspectivas de autonomia frente ao governo as forças majoritárias da CNTE, União Nacional dos Estudantes/UNE e Confederação Nacional dos Trabalhadores em Estabelecimentos de Ensino/Contee declararam, em janeiro de 2005, por ocasião do Fórum Social Mundial, que não tinham mais consenso em relação à pauta do Fórum Nacional em Defesa da Educação Pública e, por isso, na prática, esse Fórum deixou de funcionar como espaço aglutinador das lutas educacionais. No fulcro da discórdia o conflito entre as agendas dos sindicatos autônomos e as políticas do governo Lula da Silva, em especial: Programa Universidade para Todos/PROUNI, Lei de Inovação Tecnológica, Exame Nacional de Desempenho de Estudantes/ENADE, Educação a Distância e inúmeros projetos de lei contrários ao PNE: Proposta da Sociedade Brasileira (2014, p. 14).

A adoção da estratégia defensiva não foi fruto da vontade dos educadores, mas decorrência das condições contraditórias que emergiram das lutas entre classes e frações de classe e as novas ofensivas do capital, e o Estado de feição neoliberal, sobre o conjunto da classe trabalhadora brasileira. Uma análise, mesmo preliminar, de alguns elementos que estão no cerne da progressiva perda da força coletiva do movimento de educadores alinhados à defesa do caráter público da educação em âmbito nacional, aponta para a evidência de que as dificuldades expressas no movimento de educadores estão relacionadas às mudanças de caráter estrutural, que vem alterando substancialmente, as relações entre as classes, no contexto de movimentos de ofensiva permanente da burguesia pela hegemonia do capital.

Um aspecto que salta aos olhos é o fato de termos tido nos últimos anos, com o avanço das políticas neoliberais no Brasil, significativas mudanças no seio da classe dominante. O crescimento substancial da nova burguesia de serviços, decorrente da ampliação do setor privado e da retração das políticas públicas, é um sintoma desta mudança que se expressa de modo marcante no contexto mais recente, mas que é resultado da histórica influência dos setores privatistas na educação brasileira. Desde a apresentação do Plano de Desenvolvimento da Educação (BRASIL, 2007), pelo governo Lula da Silva, e mais recentemente com a aprovação do PNE, no governo Dilma Rousseff, temos visto que a agenda política deste robusto setor, cujos principais representantes estão reunidos atualmente no movimento Compromisso Todos pela Educação, vem sendo adotada sistematicamente pelos governos.

No Brasil, a recomposição do bloco de poder que entrou em crise no final da ditadura civil-militar vem sendo liderada pelo setor financeiro, a fração burguesa mais poderosa no capitalismo de hoje e, seguramente, o principal sustentáculo do Estado-Maior da alta burguesia. O TPE [Todos pela Educação] foi convocado justo pelo setor bancário, liderado pelo 
Itaú, em articulação com o setor de commodities, no caso, siderúrgico, dirigido pelo organizador de outra iniciativa empresarial para intervir na educação, o movimento Brasil Competitivo, Jorge Gerdau Johannpeter. Este dirigente empresarial atualmente é um dos principais assessores da presidenta Dilma Rousseff para a continuidade da reforma do Estado [...] (EVANGELISTA \& LEHER, 2012, p. 6).

A organicidade deste setor pode ser observada, mais concretamente, através do avanço do empresariamento do ensino superior, que corresponde, segundo dados do Censo (2014), a cerca de 76\% do total de matrículas. Uma das estratégias que impulsionou a expansão do setor privado nos últimos anos foi a implementação de mudanças nas regras do Fundo de Financiamento Estudantil (FIES) que colocou os juros dos contratos abaixo da inflação, assegurando queda de $6,5 \%$ para $3,4 \%$ ao ano, facilitou o financiamento, tornando possível acessá-lo a qualquer momento, relaxou a exigência de fiador, e alongou o prazo de quitação. Como efeito dessas medidas tivemos, entre outros, o aumento total gasto por ano pelo governo federal com o crédito estudantil, que de 2010 até o ano passado, foi de 13 vezes - passando de $\mathrm{R} \$ 1,1$ bilhão naquele ano para $\mathrm{R} \$ 13,7$ bilhões, em 2014.

A principal consequência das novas regras foi o crescimento nas transferências para grupos de educação. O Kroton-Anhanguera, por exemplo, foi a empresa que mais recebeu pagamentos do governo federal em 2014. Doze mantenedoras do grupo receberam juntas mais de $\mathrm{R} \$ 2$ bilhões - o dobro do que a Embraer, que fabrica aviões militares, e a Odebrecht, responsável por dezenas de obras pelo País. Em 2010, não havia nenhuma empresa de educação entre as 70 que mais recebiam do governo federal. Já no ano passado, sete empresas figuraram nessa lista milionária. Os grupos maiores como o Kroton-Anhanguera são donos de várias empresas que aparecem isoladamente na lista ( 7 gráficos que explicam a farra do financiamento estudantil, 2015, p.1 ).

Segundo Leher (2014, p. 15) a organicidade do capital também ficou "evidente nas lutas pelo PNE (Lei 13.005/2014)", bem como no documento final, em que ficou "aberto o caminho para a reconfiguração da educação pública" de acordo com os interesses dos setores privatistas.
A experiência das ofensivas do capital, evidente nas lutas pelo PNE, em que entidades corporativas patronais, como a CNI e Confederação Nacional de Agricultura (CNA), coalizões empresariais, como o Todos pela Educação, fundações estrangeiras vinculadas ao grande capital rentista, como a Open Society Foundations liderada por George Soros, atuaram de modo intenso, possibilitando a visceral incorporação da agenda do Todos pela Educação e da CNI nas políticas educacionais vigentes no país permitem concluir que os setores dominantes atuaram organizados como 'classe para si' no terreno educacional.

Outro aspecto que podemos ressaltar são as transformações que vem ocorrendo no mundo do trabalho, com a inserção dos princípios do toyotismo, que tem alterado as relações de trabalho de modo geral, com forte impacto na categoria docente como um todo. Sem adentrar aqui nas questões específicas que dizem respeito à gestão do trabalho e às "novas conformações da reestruturação produtiva do capital no século XXI" (ALVES, 
2011), importa-nos compreender de que modo tais transformações contribuíram com o refreamento da capacidade de luta coletiva dos educadores.

A reestruturação produtiva enquanto acumulação flexível foi, antes de tudo, um resultado histórico-social da luta de classes e da série de derrotas das instituições defensivas do trabalho no campo econômico, político e ideológico, no decorrer das décadas de 1970 e 80 (idem, p. 20).

A categoria docente foi fortemente atingida por essas transformações que alcançaram a totalidade social, impactando no âmbito das instituições educacionais. A incorporação dos princípios de gestão empresarial pelas instituições educacionais públicas trouxe significativas mudanças para o trabalho docente. A atual intensificação, precarização e individualização, via processos meritocráticos, implicou no próprio esvaziamento do sentido do trabalho do professor, e com ele a agudização do estranhamento do trabalhador em relação à sua atividade laboral, dificultando a luta e diminuindo a atuação política dos educadores nos espaços disponíveis, colocando em segundo plano, a resistência ativa [sobretudo coletiva], nos termos defendidos por Saviani.

Entre os inúmeros efeitos possíveis dessas transformações podemos apontar o adoecimento, ilustrado em matéria recentemente publicada pelo jornal O Globo que afirma que no ano 2014 cerca de 1.210 professores "da rede estadual do Rio de Janeiro ficaram licenciados por depressão ou transtornos mentais". O número corresponde $12,5 \%$ do total dos 9.680 mil docentes que tiraram licença no ano passado, perdendo apenas para os $33 \%$ licenciados por problemas ósseos e fraturas. Embora a ilustração esteja centrada na situação particular da rede estadual do Rio de Janeiro, têm sido cada vez mais comuns estudos que demonstram ser esta uma questão preocupante que atravessa a profissão docente da atualidade. Entre inúmeros trabalhos produzidos nesse sentido podemos citar: Costa \& Braga (2013), Léda (2009), Léda \& Mancebo (2011), Oliveira (2004), Sguissardi \& Silva Júnior (2009), Silva \& Silva Júnior (2010), entre outros.

É possível que o conjunto de alterações históricas, aqui apenas indicadas algumas delas, tenham resultado na perda gradativa da subjetividade de classe, levando os educadores a um profundo processo de individualização, que se expressa na busca de saídas individuais para os problemas enfrentados, gerando, conforme temos visto, sofrimento e adoecimento da categoria docente, como forma de resistência (SELIGMANSILVA, 2011).

Este breve resgate histórico dos movimentos de luta em defesa da educação pública e a indicação de alguns entraves dela mostram que os problemas da educação nacional continuam a exigir a mobilização de forças políticas coletivas, no sentido de empreenderem a luta necessária para que se construam efetivamente soluções para os históricos problemas que se tornam agudizados na atual fase do capitalismo.

\section{A LUTA EM DEFESA DA EDUCAÇÃO PÚBLICA: A HISTÓRIA EM MOVIMENTO}

Como já afirmamos anteriormente, compreendemos que o refreamento da luta em defesa da educação pública não foi fruto da vontade dos educadores, mas decorrência das condições contraditórias que emergiram das lutas entre classes e frações de classe e as novas ofensivas do capital. As contradições que produzem os movimentos de avanços e recuos desta luta são próprias do modo de produção capitalista, o que significa que estamos em permanente movimento. 
Não obstante as perdas sofridas com a ofensiva neoliberal, observamos que as tentativas de reorganização da luta foram constantes, embora nem sempre tenham ultrapassado seus limites e resultado em força coletiva capaz de alterarem as condições históricas da educação brasileira. Nesse sentido, Leher destaca que embora seja possível identificar a eclosão, a partir de 2011, de um número significativo de greves e lutas estudantis, que tinha como pressuposto a defesa da educação pública, tais iniciativas "carecem da força da unidade de ação da classe".

De fato, as greves da educação básica que eclodiram de modo intenso a partir de 2011 em todos os estados e nos principais municípios; a grande greve das universidades e dos Institutos Federais de Tecnologia, em 2012; as lutas estudantis e, notadamente, o clamor da juventude que foi às ruas para afirmar que "educação não é mercadoria", nas Jornadas de Junho de 2013, carecem da força da unidade de ação da classe (idem, p.15).

Recentemente, como expressão da retomada da organização política da categoria docente, articulada com outras categorias da classe trabalhadora, estudantes, entre outros, foi realizado no Rio de Janeiro, nos dias 8, 9 e 10 de agosto de 2014, o Encontro Nacional de Educação (ENE) reunindo aproximadamente 2,3 mil participantes, provenientes de todo o país, e agregando entidades nacionais e internacionais. Leher (idem, p. 18) afirma que o que o ENE "sinaliza de novo nas lutas pela educação pública é que os movimentos, sindicatos e demais protagonistas não poderão se limitar a reagir diante da ofensiva dos governos e do capital" mas lutar contra as ofensivas, construindo coletivamente nova agenda para a educação pública. Em síntese:

\footnotetext{
Essa avaliação levou um conjunto de entidades a sustentar como necessário um novo ponto de partida para as lutas em defesa da educação pública que superasse as iniciativas anteriores, como o Fórum Nacional em Defesa da Escola Pública. A avaliação compartilhada era de que seria necessário ampliar o escopo das lutas, incluindo outras organizações da classe trabalhadora, possibilitando unidade de ação e a construção de uma agenda socialista para a educação pública: esses são os objetivos do Encontro Nacional de Educação (idem, p. 15).
}

Conforme sinalizamos, novas iniciativas vêm sendo tomadas no sentido de enfrentar os problemas da educação nacional que, dado sua complexidade, exigem a mobilização de forças cada vez mais significativas. Compreendemos que a superação desses históricos problemas requer a mobilização de forças sociais que promovam lutas para além das "estritamente educacionais, levadas a cabo por trabalhadores da educação e estudantes", uma vez que "somente no contexto das grandes jornadas antissistêmicas essas lutas podem ter efetividade" (idem, p. 20). Assim, estudos que investiguem em profundidade as especificidades dessa história de luta, seus limites e avanços, são fundamentais para orientar esse necessário novo ponto de partida. 


\section{REFERÊNCIAS}

ARELARO. Lisete Regina Gomes. Resistência e submissão: a Reforma Educacional na década de 1990. Artigo do livro: O cenário Educacional Latino-americano no limiar do século XXI. Reformas em debate. Campinas, SP: Autores Associados, 2000.

BOLLMANN, Maria da Graça Nóbrega. Revendo o Plano Nacional de Educação: Proposta da Sociedade Brasileira. Educ. Soc., Campinas, v. 31, n. 112, p. 657-676, jul.-set. 2010.

BRASIL. Ministério da Educação. INEP. Censo da Educação Superior. Disponível em:〈http://portal.inep.gov.br/superior-censosuperior-sinopse>. Acesso em: 30. Mar. 2015.

BUFFA, Ester. Ideologias em conflito: escola pública e escola privada. São Paulo, Cortez \& Moraes, 1979.

COSTA, Gleiciane Mende; BRAGA, Lucelma Silva. Mundo do trabalho em tempos de mundialização do capital: repercussões no trabalho de docentes de instituições públicas de ensino superior. In: XXI Seminário Nacional UNIVERSITAS/ Br, São Carlos. Anais do XXI Seminário Nacional Universitas/Br, 2013

COUTINHO, C. N. O Estado brasileiro: gênese, crise, alternativas. In: Debates e síntese do seminário Fundamentos da Educação Escolar do Brasil Contemporâneo. Rio de Janeiro. Escola Politécnica de Saúde Joaquim Venâncio/ Fiocruz, 2007.

CURY, Carlos Roberto Jamil. Ideologia e educação brasileira. São Paulo: Cortez e Moraes, 1978.

CUNHA, Luiz Antônio. Educação e Desenvolvimento Social no Brasil. Rio de Janeiro, F. Alves, 1975.

CUNHA, Luiz Antônio \& GÓES, Moacyr .O golpe na educação. Rio de Janeiro: Jorge Zahar, Ed. 1985 (Brasil os anos de autoritarismo, análise, balanço, perspectivas).

CUNHA, Luiz Antônio. Educação, Estado e democracia no Brasil. São Paulo: Editora Cortez; Niterói, RJ: Editora da Universidade Federal Fluminense; Brasília, DF: FLACSO do Brasil 1991.

EVANGELISTA, O.\& LEHER, R. Todos Pela Educação e o episódio Costin no MEC: A Pedagogia Do Capital em ação na política educacional brasileira.Trabalho Necessário www.uff.br/trabalhonecessario; Ano 10, No 15/2012.

FÉLIX, Maria de Fátima Costa. Administração escolar: um problema educativo ou empresarial?. São Paulo: Cortez: Autores Associados, 1984.

FERNANDES, Florestan. Nova República?. Rio de Janeiro: Jorge Zahar Ed. 1986.

FERNANDES, Florestan. A transição prolongada: o período pós-constitucional. São Paulo: Cortez, 1990.- (Biblioteca da Educação. Série economia e política:v.2).

FREITAG, Bárbara. Escola, Estado e sociedade. São Paulo, Edart, 1977.

FRIGOTTO, Gaudêncio. A produtividade da escola improdutiva. São Paulo, Cortez, 1984.

GERMANO, José Willington. Lendo e aprendendo: a Campanha de Pé no Chão Também de Aprende a Ler. São Paulo, Cortez, 1985. 
LÉDA, Denise Bessa. Trabalho docente no ensino superior: análise das condições de saúde e de trabalho em instituições privadas do estado do Maranhão. 2009. Tese (Doutorado em Psicologia Social)-Universidade do Estado do Rio de Janeiro, Rio de Janeiro, 2009.

LEDA, D. B., MANCEBO, M. REUNI: heteronomia e precarização da universidade e do trabalho docente. Educação e Realidade, v. 34, n. 1, p. 49 - 64, jan/abril 2009. Disponível em: <http://seer.ufrgs.br/educacaoerealidade/article/view/8457/4922>. Acesso em: $1 \mathrm{dez}$. 2011.

LEHER, Roberto. Organização, estratégia política e o Plano Nacional de Educação. Blog Marxismo 21, 11 de agosto de 2014. Disponível em: http://marxismo21.org/wpcontent/uploads/2014/08/R-Leher-Estrat\%C3\%A9gia-Pol\%C3\%ADtica-e-Plano-NacionalEduca\%C3\%A7\%C3\%A3o.pdf. Acessado em 06 de abril de 2015.

LOMBARDI, J.C. Reflexões sobre educação e ensino na obra de Marx e Engels. Campinas, SP: Tese (livre docência) - Universidade Estadual de Campinas, Faculdade de Educação, [s.n.], 2010.

MARTINS, L. M. As aparências enganam: divergências entre o materialismo histórico dialético e as abordagens qualitativas de pesquisa. In: Anais da 30a Reunião Anual daAssociação Nacional de Pós-graduação e Pesquisa em Educação. Cd-rom. Caxambu: ANPED, 2007.

MINTO, L. W. Educação e Lutas Sociais no Brasil pós-ditadura: da democratização à ausência de alternativas. Revista HISTEDBR On-line, Campinas, nº 54, p. 242-262, dez2013.

MORAES, Maria Célia Marcondes de. Recuo da teoria: dilemas na pesquisa em educação. In: Intelectuais, conhecimentoe espaço público - Anais da $24^{a}$ Reunião Anual da ANPED (recurso eletrônico). Caxambú: ANPED, 2001.

NAVARRO, Ignez Pinto. ANDES-SN: Um sindicato de intelectuais. Mato Grosso: ADUFMT, 2001.

NETO, L. Depressão tira 1.210 professores de sala da rede estadual do Rio. O Globo, Rio de Janeiro, 01 de março de 2015. Disponível em

http://oglobo.globo.com/sociedade/educacao/depressao-tira-1210-professores-de-sala-darede-estadual-do-rio-15469366. Acesso em 03 de março de 2015.

OLIVEIRA, Dalila Andrade. A reestruturação do trabalho docente: precarização e flexibilização. Educ. Soc., Campinas, vol. 25, n. 89, p. 1127-1144, Set./Dez. 2004.

Disponível em http://www.cedes.unicamp.br.

PINASSI, M. O. O lulismo, os movimentos sociais no Brasil e o lugar social da política. Herramienta, ano XV, n. 46, mar. 2011. Disponível em:〈http://www.herramienta.com.ar>. Acesso em: 13 jun. 2012.

ROSAR, Maria de Fátima Félix. Para "navegação venturosa” dos anos 80, contávamos com boas lentes de aumento e conseguíamos ver muito além do horizonte. Palestra proferida no ciclo de debate HISTEDBR, 2005.

RIBEIRO, Maria Luiza Santos. História da Educação Brasileira. São Paulo, Cortez e Moraes, 1979.

SAVIANI. Dermeval. Educação Brasileira: estrutura e sistema. Campinas: Autores Associados, 1979. 
SAVIANI, D. História das Ideias Pedagógicas: reconstruindo o conceito. In: FARIA FILHO, L. M. (ORG). Pesquisas em História da Educação: Perspectivas de análise, objeto e fonte- Belo Horizonte: HG edições, 1999, p. 9-24.

SAVIANI, Dermeval. O Debate Teórico e Metodológico no Campo da História e sua Importância para a Pesquisa Educacional. In: SAVIANI, D; LOMBARD, J. C.; SANFELICE, J. L. História e historia da educação. Campinas: Autores Associados/ HISTEDBR, 1998.

SAVIANI, Dermeval. História das ideias pedagógicas no Brasil. Campinas, SP: Autores Associados, 2007.- (Coleção Memória da educação)

SELIGMAN-SILVA, E. Trabalho e desgaste mental: o direito de ser dono de si mesmo. São Paulo: Cortez, 2011.

SGUISSARDI, Valdemar; SILVA JÚNIOR, João dos Reis. O trabalho intensificado nas Federais: pós-graduação e produtivismo acadêmico. São Paulo: Xamã, 2009.

SILVA, Eduardo; SILVA JÚNIOR, João dos Reis. Estranhamento e desumanização nas relações de trabalho na instituição universitária pública. Campinas: Histedbr Online, $\mathrm{n}$. especial, p.223-238, ago 2010.

TRICHES, Jocemara. Organizações multilaterais e curso de pedagogia: a construção de um consenso em torno da formação de professores. Dissertação (Mestrado em Educação) Florianópolis: PPGE/UFSC. 218 p, 2010.

WARDE, Mirian Jorge. O Manifesto de 32: reconstrução educacional no Brasil. Revista da Associação Nacional de Educação, Ano 1, nº 5, 1982.

WARDE, Mirian Jorge. Liberalismo e Educação. Tese de Doutorado. São Paulo, 1984. 7 gráficos que explicam a farra do financiamento estudantil, Blog do Estadão, 4 de março de 2015. Disponível em http://blog.estadaodados.com/fies/. Acesso em 5 de março de 2015.

\footnotetext{
${ }^{1}$ Artigo reformulado a partir de texto apresentado na comunicação oral da XII Jornada do HISTEDBR e X Seminário de Dezembro, realizado na Universidade Estadual do Maranhão- Centro de Estudos Superiores de Caxias - CESC, de 02 a 04 de dezembro de 2014.

${ }^{2}$ Docente na Universidade Federal do Maranhão, CCAA- UFMA, e pesquisador do HISTEDBR, Gt- MA.
}

Recebido: maio/2015 Aprovado: jun/2015 